\title{
ADVANCEMENT OF FRACTIONALLY DIFFERENCED GEGENBAUER PROCESSES WITH LONG MEMORY
}

\author{
GNANADARSHA SANJAYA DISSANAYAKE
}

(Received 2 November 2015; first published online 12 May 2016)

2010 Mathematics subject classification: primary 62M10; secondary 60H40.

Keywords and phrases: long memory time series, Gegenbauer processes, Monte Carlo experiment.

The class of long memory time series models involving Gegenbauer processes is investigated in detail in terms of formulation, parameter estimation, prediction and testing. Corresponding truncated AR (autoregressive) and MA (moving average) approximations driven by Gaussian white noise are analysed through state-space modelling and Kalman filtering to assess the viability of estimating techniques. The optimal approximation option is employed to proceed with the estimation of model parameters. The resulting mean-square errors are validated by the predictive accuracy to establish an optimal lag order through a large-scale simulation study. It is shown that the use of this newly established lag order for a real data application provides benchmarks which are comparable to and mostly better than a number of existing results in the literature. It is followed by an execution of this technique to extract and assess seasonal models through a Monte Carlo experiment. Thereafter empirical applications are provided.

The above approach has been extended to model fractionally differenced Gegenbauer processes with conditional heteroskedastic errors and models with seasonality (see [1]). This paper motivated the development of the model in the thesis. Potential applications are provided. In addition, quasi-likelihood-type ratio tests have been developed for testing unit roots, stationarity versus nonstationarity and Gegenbauer long memory versus standard long memory.

The results of the thesis have been reported in a series of working papers of the School of Mathematics and Statistics of the University of Sydney and in the papers $[2,3]$.

Thesis submitted to the University of Sydney in February 2015; degree awarded on 16 June 2015; principal supervisor Shelton Peiris, co-supervisors Qiying Wang and Tommaso Proietti.

(C) 2016 Australian Mathematical Publishing Association Inc. 0004-9727/2016 \$16.00 


\section{References}

[1] G. S. Dissanayake and M. S. Peiris, 'Generalized fractional processes with conditional heteroskedasticity', Sri Lankan J. Appl. Statist. 12 (2011), 1-12.

[2] G. S. Dissanayake, M. S. Peiris and T. Proietti, 'State space modeling of Gegenbauer processes with long memory', Comput. Statist. Data Anal., Special issue of Ann. Comput. Financ. Econom., to appear, doi:10.1016/j.csda.2014.09.014.

[3] G. S. Dissanayake, M. S. Peiris and T. Proietti, 'Estimation of generalized fractionally differenced processes with conditionally heteroskedastic errors', in: International Work Conference on Time Series, Proc. ITISE 2014 (eds. I. R. Ruiz and G. R. Garcia) 871-890. Copicentro Granada S L, ISBN 978-84-15814-97-9.

\section{GNANADARSHA SANJAYA DISSANAYAKE,}

School of Mathematics and Statistics,

University of Sydney, New South Wales 2006, Australia

e-mail: gnanadarshad@gmail.com 